\title{
UNAMUNO Y SCHOPENHAUER: EL MUNDO ONÍRICO
}

\author{
Pedro RIBAS \\ Universidad Autónoma de Madrid
}

Miguel de Unamuno fue un destacado conocedor de la filosofía alemana de la Ilustración y del siglo XIX. Entre los nombres de autores alemanes que mencionó a menudo o leyó con alguna profundidad cabe recordar al ilustrado Kant, al vitalista Nietzsche, a los idealistas Hegel y Schopenhauer. Por supuesto, estos no son los únicos tïlósofos alemanes a los que leyó. Cabría también mencionar a Marx, cuya obra El capital se halla en el Archivo de Unamuno con subrayados (en el libro I) que demuestran su lectura por el joven bilbaíno, sobre todo durante su etapa socialista ${ }^{\prime}$. Podrían mencionarse otros varios nombres como Herder, Humboldt, Goethe, Hölderlin y una buena lista de escritores, tanto poetas como dramaturgos, científicos, teólogos, etcétera.

El caso de Schopenhauer me parece algo curioso. Me refiero a que no es de los muy aireados por Unamuno, que no alardeó nunca de ser schopenhaueriano o de que cl autor de El mundo como voluntad y representación fuese una figura clave de sus preferencias. Y, sin embargo, hay bastantes motivos para sostener que Unamuno lo conoció pronto, leyó sus obras y sintió interés por su filosolía. El asunto me parece tanto más digno de atención y esclarecimiento cuanto que abundan en la bibliografía sobre Unamuno las referencias a un paralelismo e incluso a una influencia de Schopenhauer sobre Unamuno.

1 Sobre esta etapa véase Unamuno (1976). 


\section{Algunos datos sobre la lectura de Schopenhauer}

En la correspondencia de Unamuno con su amigo Pedro Múgica, que reside en Berlín, puede verse que su contacto con Schopenhauer es bastante temprano. El 4 de junio de 1890 le escribe a Múgica lo siguiente: "En los diez años que llevo de traducir alemán he conseguido leer bastante bien a Goethe, Lenau, etc.. También me gusta Voss y mucho Schopenhauer." (Fernández Larraín, 1965, pág. 109)

En esta misma correspondencia podemos comprobar que lee a Schopenhauer en los años 91 y 92 . Y en el 93 le cuenta Unamuno a Múgica la edición de obras completas que posee en casa y le pregunta si han salido todos los escritos póstumos, "porque teniendo ya todas sus obras me gustaría tener completo el tal Nachlass." (Fernández Larraín, 1965, pág. 209)

Los subrayados y anotaciones que encontramos en las obras de Schopenhauer existentes en la Casa-Unamuno no echan demasiada luz sobre la posible influencia del alemán en el español, ya que aluden especialmente a los nombres de españoles mencionados por el primero. A juzgar por estas anotaciones, no fue el sistema filosófico de Schopenhauer lo que llamó la atención de Unamuno, sino más bien lo que podríamos denominar la sabiduría de la vida o escritos populares como los Parerga y paralipomena. Conviene subrayar en todo caso que Schopenhauer es el único autor, entre los filósofos alemanes importantes, traducido por Unamuno. Me refiero a Über den Willen in der Natur, que fue traducido por el catedrático de Salamanca en 1900 para la editorial La España Moderna con el título Sobre la voluntad en la naturaleza.

En la correspondencia Unamuno-González Serrano pueden hallarse referencias a esta traducción, cuyo proyecto debió ser bastante anterior a 1900, ya que el 14 de octubre de 1896 le escribe Urbano González Serrano:

Como motu proprio usted recuerda la promesa de traducción del libro de Schopenhauer, le agradezco muy de veras que la haga y le anticipo las gracias previamente y me regodeo con el placer que me ha de producir su lectura." (Salamanca. Archivo Unamuno, cartas de Urbano González Serrano)

El 3 de marzo de 1897 le escribe González Serrano en términos que dan a entender que la traducción estaba ya hecha. He aquí el texto de la carta:

Recibí la traducción de Schopenhauer y me parece superfluo decir a V. cuánto y cuán de veras se la agradezco. La he de leer despacio y después he de dársela a Berrute ${ }^{2}$. Presumo que no pensará V. por ahora utilizarla y que por tanto podré tenerla en mi poder hasta que usted la necesite. (Archivo Unamuno, cartas de González Serrano)

De nuevo, el 14 de marzo de 1897 le dice González Serrano a Unamuno lo siguiente respecto de esta traducción:

2 En el texto original de la carta no se lee bien este nombre. 
Gracias mil por la traducción de Schopenhauer, cuya Jectura, aun sin comenzarla, me da ya sabor y perfume. Quiero hacerla, evacuando citas y leyendo a la vez la traducción de Catacuzene, ${ }^{3}$ que me ha de dar Berrute ${ }^{4}$ otras obras del gran humorista. (Archivo Unamuno, cartas de González Serrano)

Por fin, el 8 de marzo de 1900 le comunica González Serrano. "En este momento recibo la traducción de Schopenhauer, que volveré a leer. Gracias." Ignoro por qué dio tantas vueltas esta traducción, si ya estaba hecha en 1897. Pero, en lugar de indagar ahora sobre ello, cosa que pienso hacer en otro lugar, prefiero aquí proseguir la comparación del pensamiento de ambos autores.

Por de pronto, parece claro, tanto a partir de las referencias de Unamuno a Schopenhauer como partiendo de una comparación de la obra de ambos autores, que lo que más interesó a Unamuno fue la estética. Por ejemplo, en 1896, en el ensayo "La regeneración del teatro español" encontramos el siguiente texto: "La impresión trágica que tan bien estudió Schopenhauer." (Unamuno, 1960, III, pág. 349) Volveré sobre ello más adelante.

Interesa, pues, destacar en qué campos pudo ser importante la lectura de Schopenhauer. Pudo ser importante, con esta expresión intento evitar hablar directamente de influencia de Schopenhauer en Unamuno, ya que es bastante difícil probar una influencia notable de algún autor sobre el catedrático de Salamanca. Por supuesto que pueden probarse influencias en él. El ambiente cultural del Madrid de 1880-84 fue una notabilísima influencia en la época de formación intelectual de Unamuno: el krausismo, el positivismo, el eclecticismo y la neoescolástica dejaron en él su huella. Pero todas ellas constituyen corrientes, son el clima intelectual de un momento, no el pensamiento de un autor singular. Cuando nos referimos a un solo autor, el asunto es más complicado, porque Unamuno fue un devorador de libros, un lector de todo tipo de escritos. Más que de influencia de un autor, se puede hablar de proximidad, de confluencia o de reacción ante él. Veamos, pues, en qué campos pudo confluir con Schopenhauer.

\section{La vida es sueño}

Como se sabe, después de su primera novela publicada, Paz en la guerra, desaparece el escenario de las novelas de Unamuno. La siguiente novela, Amor y pedagogia, nos introduce ya en conflictos que no se desarrollan en un medio real ni son resultado de enfrentamientos históricos entre colectividades sociales, sino que tienen que ver con el individuo como tal. Al quedar suprimido el escenario, los personajes producen la impresión de carecer de consistencia. Y es que Unamuno ha abandonado el naturalismo anterior para colocarse en lo que podemos llamar el

Nombre que tampoco leo bien en el original.

Véase la nota 2. 
cxistencialismo o preexistencialismo, al menos en el sentido de presentar individuos que buscan un camino particular, que toman decisiones y que se preguntan a sí mismos sobre tales decisiones. En una palabra, los personajes de Amor y pedagogia, como los de Niebla, no se mueven sobre un terreno firme, sino que se hacen y se deshacen delante del lector según van actuando: son como individuos sin raíces y con una especial preocupación por afirmarse frente a cierta inseguridad acerca de sí mismos. Su vida, la de cada uno, consiste precisamente en preguntarse acerca de su propia condición como individuo. No es casual que Unamuno titulase un ensayo suyo de noviembre de 1898 "La vida es sueño". En este artículo, publicado en La España Moderna, después del llamado desastre, encontramos una oposición al progresismo que marca la ruptura producida en las posiciones de Unamuno. Así, en los artículos de Eco de Bilbao, de La Lucha de Clases y de Ciencia Social defendía que el progreso era enriquecimiento del medio ${ }^{5}$ y que tenía, por tanto, un sentido social, en la medida en que el individuo, como tal, podía encontrar satisfacción a sus necesidades y remedio (al menos parcial) a sus limitaciones gracias al trabajo de todos y, en definitiva, a la convivencia en la colectividad. El individuo, en una palabra, era considerado como inserto en un dominio 0 contexto social. Aquí, en "La vida es sueño", encontramos, en cambio, una llamada a la paz interior. Se pregunta Unamuno: " ¿Viven mejor, con más paz interior, los ciudadanos concientes de una gran nación histórica que los aldeanos de cualquicr olvidado rincón?" (Unamuno, 1960, III, pág. 409). Este planteamiento parece un preludio de ese pueblo sin historia que nos presentará más tarde en San Manuel Bueno, mártir.

Hay en esta contraposición de la paz interior y del progreso, del ruido, de la gloria, del honor nacional, etcétera, una positiva valoración del estado de miseria e ignorancia en que vive el pueblo, gracias a que éste se halla "en paz y en gracia de Dios en su atraso e ignorancia." (Unamuno, 1960, III, pág. 414). Claramente protesta Unamuno de que se sacrifique el individuo a la colectividad y aunque esta protesta tiene en el ensayo "La vida es sueño" resonancias antipatrioteras típicas del Unamuno de los años 90 , hay un acento en el individuo y, sobre todo, en la vida interior de éste, que recuerdan todo lo contrario de lo que afirmaba en Eco de Bilbao o en "La dignidad humana".

En la novela Amor y pedagogia, la primera que publica después de la crisis de 1897, queda patente la afición que Unamuno toma a la técnica de Maese Pedro, la de mover muñecos en el escenario. En carta a su amigo Ilundain, escribe refiriéndose a esta novela:

Escribe Unamuno en su ensayo "La dignidad humana", publicado en Ciencia Social en 1896: "Es casi incuestionable que la sociedad progresa más que el individuo, que es el ámbito social el que más adelanta, que excede en más nuestra ciencia a la de los griegos que nuestra capacidad mental a la suya. Nacemos en una sociedad que nos suministra medios más perfectos" (Unamuno, 1960, III, pág. 448). 
La concepción fundamental es que el mundo es un teatro, y que en él cada cual no piensa más que en la galería; que mientras cree obrar por su cuenta, es que recita el papel que en la eternidad le enseñaron. ${ }^{6}$

Pienso que hay una complementariedad entre el abandono del escenario y la pérdida de sustancialidad de los personajes. Pero, sea de ello lo que fuere, lo cierto es que Unamuno quiere mostrar almas al desnudo, sin bambalinas, sin escenario histórico o geográfico, afirmando que tales elementos externos son pura apariencia. Esto sí nos conduce a Schopenhauer, para quien la realidad, la verdadera realidad, no es la que nos rodea, sino el espíritu. El mundo es una fábula, en palabras del propio Schopenhauer.

\section{Pesimismo}

¿Por qué es pesimista Unamuno? Pesimista no sé si sería la palabra adecuada. Lo cierto es que su agonismo, que se revela especialmente en Vida de Don Quijote y Sancho, encierra un sentido de insatisfacción inherente al propio planteamiento del individuo. En efecto, éste no acepta su propia limitación, no se resigna a quedar encerrado en su yo limitado, sino que quiere salir de él para ir más allá. Como dirá más tarde en Del sentimiento trágico de la vida, quiere serlo todo. Pero, a la vez, no quiere dejar de ser sí mismo. La situación se hace así conflictiva y trágica. Y aquí es donde se podría hablar de cierto fondo pesimista en el pensamiento de Unamuno, en la medida en que este conflicto no encuentra solución.

Pero ¿es ésta la razón del pesimismo de Schopenhauer? No. En Schopenhauer el pesimismo nace de su sistema metafísico. Desde el momento en que el ser, lo que hay, se resuelve en voluntad y que ésta es irracional, arbitraria, caprichosa, en una palabra: mala, es claro que en lugar de aquella bondad que los escolásticos atribuían a todo ser, estamos aquí ante una concepción opuesta, una concepción según la cual la voluntad queda configurada como una fuerza dotada de propiedades que la convierten en mala, aunque Schopenhauer no la califique así, sino sencillamente como fuerza neutral. En realidad, la actitud de Schopenhauer es mucho más pesimista que la de Unamuno, ya que Schopenhauer parte del supuesto de que la voluntad, que es el númeno en términos kantianos, es la fuente de donde deriva el carácter de cada individuo? ${ }^{7}$ Y si es así, no se puede cambiar: la voluntad es lo

\footnotetext{
"Carta de Unamuno a Jiménez Ilundain, 19.10.1900; cit. por Manuel García Blanco en Unamuno, 1958, II, pág. 20.

7 Schopenhauer no dice que la voluntad sea mala; él nunca explica la relación entre la voluntad y el mal directamnete, sino que presenta la la primera como causante del segundo. Schopenhauer lo formula así: "Esa gran impetuosidad de la voluntad es, por sí misma y de forma inmediata, una fuente permanente de sufrimiento. Primeramente, debido a que todo querer, en cuanto tal, nace de la carencia, esto es, del sufrimiento. (De ahi que, como sabemos por el libro III, el momentáneo silencio de todo querer que se produce en cuanto nosotros, como sujeto del conocer $\sin$ voluntad [correlato de la idea], nos hallamos entregados a la contemplación estética, sea una razón principal del gozo en lo estético).
} 
que hay detrás de las apariencias o del mundo fenoménico, y, por tanto, constituye el ser verdadero de todo cuanto existe. No estamos aquí ante un defecto del ser (tal era el mal para los escolásticos), sino que estamos ante el ser mismo. En una palabra, no se puede cambiar el carácter de la voluntad.

En Unamuno, en cambio, el pesimismo nace de una insatisfacción debida a la limitación del individuo, pero si éste tiene un arma para combatir (independientemente de que el combate tenga visos de llegar a una victoria) es el deseo, el deseo de sobrepasar y el rechazo al conformismo ${ }^{8}$. En Schopenhauer, por el contrario, librarse del mal es librarse del deseo.

El mundo interior en el que nos introduce Unamuno es un mundo de conflicto y de insatisfacción. O dicho en otras palabras, está envuelto en un tono pesimista, que es un punto de acercamiento al universo de Schopenhauer. Para éste, la vida es un continuo aspirar, esto es, tender a algo de lo que se carece. Pero llegar a alcanzar ese algo, si es que se consigue, es sólo el comienzo de otra ascensión de Sísifo. Dicho en otros términos, la vida es sufrimiento. Este mundo, lejos de ser el mejor de los posibles, como había afirmado Leibniz, es un nido de víboras, un valle de lágrimas, un infierno de dolores. Este mundo es el peor de los posibles. Por ello valdría más no haber nacido. La vida es un negocio que no cubre gastos, para decirlo en términos del propio filósofo alemán.

No obstante, este acercamiento a una visión pesimista no es del todo coincidente en ambos autores, como acabamos de ver, debido a su vinculación a un sistema metafísico en el caso de Schopenhauer. Unamuno no establece ninguna metafísica. Como filósofo, su pensamiento discurre mucho más por la vía de las preguntas, de las dudas, de los planteamientos de problemas que por la de las soluciones.

Ante todo, el español no es un autor de sistema filosófico y, mucho menos un convencido en términos dogmáticos de la verdad de tal sistema. Schopenhauer, por su parte, es uno de los últimos autores de un sistema filosófico, sistema que él defiende con uñas y dientes frente a cualquier otro, convencido de su verdad. Este punto le separa diamentralmente de Unamuno. El pesimismo de éste sólo tiene que ver con el de Schopenhauer por el hecho de coincidir ambos en rechazar una visión optimista del mundo. Por ello puede decirse que el pesimismo de los dos se sostiene en una filosofía distinta: en Schopenhauer, la doctrina de la voluntad; en Unamuno, el agonismo o quijotismo como doctrina del afirmarse en la historia, esto es, de ser hijo de sus obras, de hacerse un alma en la historia, como él mismo dijo.

\footnotetext{
En segundo lugar, debido a que, dado el encadenamiento causal de las cosas, la mayoría de los deseos han de quedar insatisfechos, y la voluntad saldrá muchas más veces contrariada que satisfecha. Tal es Ia razón de que el mucho e impetuoso querer conduzca al mucho sufrir. En efecto, todo sufrir no es ni más ni menos que querer insatisfecho y contrariado" (Schopenhauer, 1960, I, pág. 495).

\& Unamuno repite a menudo la frase del Obermann, de Sénancour, "si la nada nos está reserva$\mathrm{da}$, hagamos que sea una injusticia."
} 


\section{La razón y la voluntad}

¿Puede hablarse de un papel paralelo en cuanto a la razón y la voluntad? Con lo que hemos dicho queda ya claro que para Schopenhauer la voluntad es, no sólo el ser verdadero, sino el ser irracional. Tales presupuestos le permiten ser un buen maestro para señalar defectos, para destruir errores, para denunciar incoherencias. En cambio, para edificar, sea una teoría del conocimiento, sea una teoría de la historia, sea una norma de convivencia humana, es del todo inservible. Pero vayamos por pasos.

La razón, para Unamuno, está al servicio de la vida. Y ésta supone, a la vez, cuerpo físico, estructura biológica y capacidad intelectual. Para Schopenhauer, la voluntad es el prius y la inteligencia, lo secundario ${ }^{9}$. Claro está que, para comparar a Schopenhauer y a Unamuno acerca de la voluntad, habría que decir primero que la voluntad schopenhaueriana, en cuanto en sí, nada tiene que ver con la voluntad humana en términos psicológicos. Dicho de otra forma, la voluntad de la que habla Schopenhauer no es la voluntad humana, sino una fuerza universal que se expresa tanto en la naturaleza como en el hombre; la voluntad humana no es más que una de las formas de expresión de esa voluntad universal ${ }^{10}$. Unamuno, en cambio, habla de la voluntad en términos de la tradición filosófica occidental, que liga voluntad e inteligencia como dos facultades del ser racional que es la persona humana.

Teniendo en cuenta lo anterior, es claro que cuando hablamos de voluntad en Unamuno y en Schopenhauer, hablamos de conceptos muy distintos, debido a que el sistema filosófico del primero tiene poco que ver con los planteamientos del segundo. Aun así, la oposición del Unamuno maduro a la idea de progreso, concebido en términos spencerianos, constituye un rasgo que puede acercarle al paralelo rechazo de la idea de progreso por parte de Schopenhauer. Incluso el acento que pone Unamuno en la instintividad puede ser un punto de contacto con Schopenhauer. Si el español habló de lógica y biótica, el alemán contrapone el concepto y la idea. El concepto, para Schopenhauer, es útil y necesario en la ciencia, ya que reduce la variedad a unidad, pero es estéril en el arte. El concepto es como un depósito en el que cada una de las cosas guardadas en él se halla separada o se puede separar, pero del que no puede extraerse más de lo que contiene. La idea, en cambio, se

"El rasgo fundamental de mi doctrina, lo que la coloca en contraposición con todas las que han existido, es la total separación que establece entre la voluntad y la inteligencia, entidades que han considerado los filósofos, todos mis predecesores, como inseparables y hasta como condicionada la voluntad por el conocimiento, que es para ellos el fondo de nuestro ser espiritual, y cual una mera función, por lo tanto, la voluntad del conocimiento" (Schopenhauer, 1970, pág. 62).

16) La voluntad schopenhaueriana, en cuanto en sí, carece de motivación, o mejor dicho, no está sometida al principio de razón suficiente. La voluntad, en la medida en que se expresa en el cuerpo, en cuanto tiene una manifestación sensible (representación), sí está sometida a dicho principio a través del motivo. Véase a este respecto Schopenhauer, El mundo como voluntad y representación, libro II, $\$ 20$. 
parece a un organismo que crece, que produce lo que no se hallaba en él. El artista trabaja con ideas "por mero sentimiento y sin conciencia, más todavía, por instinto”. (Schopenhauer, 1960, I, pág. 330)

Esta concepción schopenhaueriana de la creación artística, como contrapuesta a la ciencia y al conocimiento de la vida cotidiana se aproxima, efectivamente, a la contraposición unamuniana de vida y razón. Y es bastante probable que, más allá del sistema filosófico de Schopenhauer, con el que Unamuno no podía estar de acuerdo, sus consideraciones estéticas fueran bien recibidas, sobre todo las relativas a la tragedia. Pero, de nuevo, hay que subrayar la incompatibilidad general del sentido del arte como metafísica que abre la vía de acceso a la idea (esto es, la identificación del sujeto con el objeto, a la contemplación, a la superación del mundo de la representación) con la concepción unamuniana del arte como creación de pasiones.

\section{Arte y metafisica}

El hecho de que Schopenhauer haya obtenido más reconocimiento entre artistas y literatos que entre filósofos profesionales no se debe tan sólo a que habló tan mal de éstos, sino a que dio al arte una dimensión que es esencial en su pensamiento. Aunque Schopenhauer se presenta como fiel discípulo de Kant, la verdad es que rompe totalmente con él. Kant señalaba en su filosofía ilustrada límites estrictos a las pretensiones de la metafísica y dejaba sentado que el terreno del conocimiento propiamente dicho era el de los conceptos, no el de las ideas. Estas no eran para él otra cosa que ideales de la razón. Schopenhauer, en cambio, señala que hay un camino por el que podemos llegar a la idea, al en sí. Este era para Kant un concepto límite, un concepto al que los humanos no podemos llegar por estar sometidos a las condiciones subjetivas y objetivas del conocimiento; o, dicho de otra forma, por estar nuestro conocimiento compuesto de materia (elemento empírico) y forma (elemento subjetivo). Pues bien, Schopenhauer - y ésta es su ruptura con Kant propone el arte como puerta de acceso al en sí, que para él es la voluntad ${ }^{11}$. "

El arte adquiere asi una dimensión metafísica, como recogerá después Nietzsche en El nacimiento de la tragedia. Allí donde fracasa la ciencia y la filosofía en cuanto sometidas al principio de razón suficiente, triunfa el arte por escaparse de este principio.

El arte nos lleva a la idea, que para Schopenhauer es la "manifestación perfecta" de la voluntad (Schopenahuer, 1960, II, pág. 470). La idea/es tomada en un

"Dcjemos ahora de lado el que sea discutible la coherencia de toda la metafísica de Schopenhauer, ya que, particndo de las propuestas de Kant, que subraya la imposibilidad de conocer el en sí, afirma que el en sí es la voluntad. 
sentido cercano al de Platón, como modelo o arquetipo de las cosas del mundo fenoménico. La idea es incognoscible desde nuestro modo habitual de conocer, esto es, desde los conceptos del entendimiento. Pero cuando somos capaces de conocer sin servirnos de tales conceptos, que están al servicio de la voluntad, y actuamos desinteresadamente, de forma que el entendimiento se sustrae a la influencia de la voluntad, entonces conocemos la idea ${ }^{12}$. Schopenhauer dice que esto es lo propio del genio. Es éste el que, por un momento (el momento de la creación), tiene el impulso suficiente para sustraer el entendimiento al dominio de la voluntad y elevarse a la idea. Es lo que consigue el pintor con su retrato, el arquitecto con la obral construida, el poeta con su poesía, el dramaturgo con su tragedia y, sobre todo, el músico con su sinfonía.

\section{Realidad y ficción}

De todo lo dicho se desprende que tanto en Schopenhauer como en Unamuno la ficción, como creación de la capacidad imaginativa, tiene un papel importante. En el caso de Schopenhauer, como filósofo que teoriza sobre el arte y su papel en la vida humana; en el caso de Unamuno, como filósofo que, además de teorizar sobre tal papel, construye su propia obra literaria.

La realidad es sueño para Schopenhauer, debido a que todo es representación. El fenómeno, para expresar en lenguaje kantiano el equivalente a la representación schopenhaueriana, se parece al sueño en el sentido de ser manifestación o signo de una realidad que se halla en otro lado. En cualquier caso, la insustancialidad de la que queda afectado el hombre y el mundo que le rodea es una de las características que acercan el planteamiento schopenhaueriano y el de Unamuno. Sin embargo, pronto nos damos cuenta de que ambos autores hablan del sueño en sentido distinto, debido al contexto general de su pensamiento.

En efecto, para Schopenhauer, la insustancialidad del hombre como individuo y de la realidad que le rodea se debe al planteamiento metafísico de todo su sistema. O, dicho de otra forma, el sistema metafísico de Schopenhauer, al distinguir un en sí, que es la voluntad, y una representación o figuras fenoménicas en que esa voluntad aparece, sume automáticamente todo cuanto aparece en una especie de mundo sublunar, sin consistencia. Lo único que tiene consistencia, lo único que tiene realidad verdadera, es la voluntad. En el sistema metafísico de Schopenhauer esta dicotomía queda establecida como piedra angular del mismo.

En Unamuno, en cambio, si se puede hablar de insustancialidad del hombre y del mundo que le rodea, es siempre de modo problemático, no como supuesto de un sistema en el que los papeles están perfectamente delimitados. Casi todo lo que

\footnotetext{
12 Véase a este respecto el capítulo XXXVIfl de El mundo como voluntad y representación.
} 
en Schopenhauer es engranaje de un sistema extremadamente rígido - en tal rigidez está su debilidad - es en Unamuno pregunta escudriñadora, sin respuesta segura. De ahí que en realidad los paralelismos o coincidencias entre el alemán y el español no signifiquen auténtica comunidad de ideas, dados los distintos contextos tcóricos en que se sustentan. Y de ahí que, aun teniendo en cuenta los elogios de Unamuno a la estética de Schopenhauer, sus acentos se encuentren colocados en elementos opuestos. Así mientras Schopenhauer celebra que en la contemplación estética el sujeto se olvide de sí mismo, de sus deseos, de sus dolores, y se eleve a la idea, sustrayéndose al principio de razón suficiente, Unamuno celebra que, gracias al dolor, el individuo se conozca en su miseria, en su existencia limitada. Augusto, por ejemplo, el protagonista de Niebla, tras sufrir la inmensa decepción de verse burlado por Eugenia, con la que estaba a punto de casarse, dice estas palabras a su amigo Víctor:

Empecé, Víctor, como una sombra, como una ficción; durante años he vagado como un fantasma, como un muñeco de niebla, sin creer en mi propia existencia, imaginádome ser un personaje fantástico que un oculto genio inventó para solazarse o desahogarse; pero ahora, después de lo que han hecho, después de esta burla, de esta ferocidad de burla, ;ahora, sí!, ahora me palpo, ahora no dudo de mi existencia real. ${ }^{13}$

Unamuno usa el arte para resaltar los conflictos del yo, las pasiones, la soledad de la conciencia, pretendiendo "desnudar el alma". Schopenhauer, en cambio, busca la armonía, que sólo puede encontrarse fuera del mundo cotidiano, el dominado por la fuerza de la voluntad, y fuera del principio de razón suficiente.

No puedo prolongar ahora esta reflexión, pero me parece extremadamente instructivo examinar la visión que tiene Schopenhauer del placer que proporciona la contemplación estética (en cuanto huida del dolor y los sufrimientos de nuestro mundo) y compararla con lo que dice Unamuno del "opio" en San Manuel Bueno, mártir. Pero, aparte de la distinta proyección que ambos han ofrecido del mundo onírico, mundo del que los dos han hablado mucho, hay algo que me parece que puede dejarse establecido como verdad incontrovertible, quizá por ser una perogrullada: Unamuno no aceptaría nunca la rigidez del sistema schopenhaueriano. En el libro $3^{\circ}$, párrafo 35 de El mundo como voluntad y representación, afirma el alemán que

en este mundo del fenómeno no hay posibilidad ni de verdadera pérdida ni de verdadera ganancia. Sólo hay voluntad: ésta es la cosa en sí, la fuente de todos los fenómenos. ${ }^{14}$

En el mundo no hay, en el fondo (en la voluntad), ni cambio ni multiplicidad: hay sólo repetición. El pensamiento de Unamuno es bastante más complejo que el

13. Unamuno (1966, pág. 146).

14 Schopenhauer (1960, I, p. 264); trad. de Ed. Porrúa, 1983, pág. 151 
de Schopenhauer, quien en su afán de claridad y sistemacidad simplifica en exceso y cae en insalvables contradicciones.

Por lo demás, un tema tan central en el autor bilbaíno como la muerte (núcleo de su agonismo), recibe en Schopenhauer un tratamiento opuesto al que ofrece Unamuno. Para éste constituye el gran problema, el drama de la finitud y limitación del individuo, finitud y limitación que Unamuno rechaza. El planteamiento ontológico de la muerte que encontramos en él consiste en presentarla como el choque del deseo de infinitud con la incertidumbre acerca de la suerte del individuo después de su último suspiro. Tal es el drama de San Manuel Bueno. Y este drama está presentado como un asunto que incumbe al individuo humano, a cada uno como tal, no como un asunto que pueda diluirse en la especie.

Schopenhauer, por su parte, presenta el problema de la muerte como un asunto que sólo es dramático por error de consideración, por contemplarlo como algo que sólo afecta a la persona, cuando, según él, es el punto de vista de la especie el que hay que adoptar, punto de vista desde el que la muerte es sólo una pérdida para el individuo. El olimpismo de las posiciones idealistas (la de Schopenhauer constituye una muestra) es la antítesis del relieve que los existencialistas prestan a las miserias y limitaciones del existente individual. Obsérvese en el siguiente texto lo que dice Schopenhauer de la muerte:

... de acuerdo con esta diferencia [entre el yo y los demás, P. R.] desaparece el nivel desde el cual se puede contemplar la muerte como la aniquilación del hombre. Pero partamos del principio de que la diferencia entre fuera de mí y en mí tiene tan sólo una base espacial, en el fenómeno, no en la cosa en sí, de que no es, por tanto, nada absolutamente real; entonces no veremos en la pérdida de la propia individualidad más que la pérdida de un fenómeno, esto es, una pérdida puramente ilusoria. (Schopenhauer, 1960, vol. II, pág. 649)

Con todo ello no pretendo decir que no hay paralelos interesantes entre Unamuno y Schopenhauer. Me refiero, más bien, a que, situado cada autor en su propio terreno, en su obra total y en la orientación global de su pensamiento, se percibe claramente que discrepan en grado sumo, hasta el punto de que las coincidencias son poco significativas por surgir de posiciones filosóficas muy diferentes. Si se quiere una imagen fácil, diría que Unamuno es existencialista, mientras que Schopenhauer se mueve en la posición opuesta, en la del pensamiento en general (Denken iiberhaupt), que es justamente la combatida por los existencialistas. 


\section{BIBLIOGRAFÍA CITADA}

SCHOPENHAUER, Arthur. 1960. Sämtliche Werke. Stuttgar/Franklurt a. M. CottaInsel Verlag, 5 vols.

- 1985. Der handschriftliche Nachlass in fünf Bänden. Heraugegeben von Arthur Hübscher. München, Deutscher Taschenbuch Verlag.

- 1983. El mundo como voluntad y representación. México, Porrúa.

- 1967. Sobre la cuádruple raiz del principio de razón suficiente. Buenos Aires, Aguilar.

- 1965. Los dos problemas fundamentales de la ética. I Sobre el libre albedrio. Buenos Aires, Aguilar.

- 1965. Los dos fundamentos de la ética. II El fundanento de la moral. Buenos Aires, Aguilar.

- 1970. Sobre la voluntad en la naturaleza. Madrid, Alianza Editorial. Traducción de Miguel de Unamuno. Prólogo y notas de Santiago González Noriega.

UNAMUNO Y JUGO, Miguel de. 1959-1964. Obras completas. Barcelona, Vergara, 16 vols.

- 1966-1971. Obras completas. Madrid, Escelicer, 9 vols.

- 1976. Artículos socialistas. Madrid, Ayuso. Edición de Pedro Ribas.

- 1993. Artículos en Las Noticias de Barcelona (1899-1902). Barcelona, Lumen. Edición de Adolfo Sotelo Vázquez.

BLANCO AGUINAGA, Carlos. 1966. "El socialismo de Unamuno, 1894-1897", Revista de Occidente, agosto de 1966, págs. 166-184.

- 1968 "De nuevo el socialismo de Unamuno (1894-1897)", Cuadernos de la Cátedra Miguel de Unamuno, núm. XVIII. Reproducido en idem, 1970, Juventud del 98, Madrid, Siglo XXI.

CEREZO GALÁN, Pedro. 1996. Las máscaras de lo trágico. Filosofía y tragedia en Miguel de Unamuno. Madrid, Trotta.

CHABRÁN, Rafael. 1983. The Young Unamuno: His Intellectual Development in Positivism and Darwinism (1880-1894). Tesis inédita, leída en la Universidad de California, San Diego-La Jolla.

- 1989. "Miguel de Unamuno: traductor de Herbert Spencer". Anuario del Departamento de Filosofía, vol. III-IV, págs. 33-43.

GÓMEZ MOLLEDA, D. 1989. Actas del congreso internacional Cincuentenario de Unamuno. Salamanca, Ediciones de la Universidad de Salamanca. 
MENDOZA NEGRILLO, Jesús. 1981. "Influencia de Schopenhauer en el voluntarismo de Unamuno". Pensamiento, núm. 146, vol. 37, págs. 171-190.

PEREZ DE LA DEHESA, Rafael. 1966. Politica y sociedad en el primer Unamuno. Madrid, Ciencia Nueva.

QUESADA, Julio (coor). 1993. Arthur Schopenhauer. Barcelona, Anthropos.

RIBAS, Pedro. 1986. "Unamuno y la cultura alemana. Convergencia con Schopenhauer", en D. GÓMEZ MOLLEDA (comp.), Volumen homenaje. Cincuentenerio de Miguel de Unamuno. Salamanca, Casa Museo Unamuno, 1986, págs. 275-294.

- 1993. "Unamuno y Schopenhauer: el psicologismo moral", en Julio QUESADA (coor.), Arthur Schopenhauer, págs. 55-62. 